\title{
NATIONAL WEALTH AND INDIVIDUAL HAPPINESS
}

\author{
Ruut Veenhoven
}

\author{
Published in Grunert, $K$ \& Oelander, F (eds.), 'Understanding Economic Behaviour', \\ Kluwer Academic Publishers, 1989, Dordrecht, pp 9-32. ISBN 0-7923-0482-9
}

\section{ABSTRACT}

Easterlin has argued that national economic prosperity is of no consequence for the individual's appreciation of life. He contends that people in poor countries are as happy as those of rich welfare states, and that decades of economic growth have left people no happier than before. This paper attacks these empirical claims, as well as the underlying theory that happiness depends largely on social comparison.

Cross-national comparison shows that people in the poorest countries of the world are actually the least happy. This appears both in a re-analysis of Easterlin own data and also in a new, more representative sample of countries. In fact, a curvilinear pattern emerges, indicating that wealth is subject to the law of diminishing utility.

Comparison over time in Western Europe shows that the post-war economic recovery was paralleled by an increase in happiness. The slower rate of growth during the last decade bas not been accompanied by a definite rise in happiness, though fluctuations in happiness have tended to follow economic ups and downs with a year's delay.

It is argued that social comparison theory cannot explain these results.

\section{INTRODUCTION}

This paper asks whether the economic prosperity of a nation contributes to the happiness of its citizens. Happiness or life satisfaction is the degree to which an individual evaluates the overall quality of his life-as-a-whole positively (Veenhoven, 1984, Ch.1). The question about the relationship between prosperity and happiness is the subject of a long-standing debate. Arguments in favour of an affirmative answer are, among others, that wealth reduces suffering from hunger and illness to a great extent, softens inequalities, and opens the way to new satisfactions, not only in the sphere of leisure and consumption, but also in the realm of arts, science, and spiritual life. Arguments to the contrary claim that affluence undermines moral consciousness and social networks, and that material comforts do not provide real satisfaction, while their production involves considerable alienation.

This discussion is not merely academic. It is of considerable consequence for economic policy making, in particular for the priority awarded to economic growth. Economic growth is a main goal of modern nations. Rational policy making requires not only finding the best means for reaching major goals, but also a systematic surveillance of these goals themselves, in order to detect inherent incompatibilities.

In spite of its long duration and its political relevance, the debate about the happiness revenues of economic growth has remained inconclusive. Plausible speculations have been advanced on both sides, and there is empirical proof of some costs as well as of various benefits. Yet the relative weights of these costs and benefits are unclear. Consequently, the net effect on happiness is unclear as well. Lacking anchorage in solid facts, the dominant opinion bas drifted with the tide of ideology.

Hence a reconsideration of the matter is due. To that end I will first review current 
research on the matter and then report new data derived from a secondary analysis of two cross-cultural studies.

\section{CURRENT VIEWS}

The favourable view of economic expansion dominated during the nineteen-fifties. The scars of the Great Depression and World War II were still being felt at that time, and it was widely believed that improvement of the material standard of living would open the way to a better life. Hence nobody was surprised when, in the early sixties, an American psychologist reported that inhabitants of rich countries found more pleasure in life than people in poor countries. This psychologist was Headly Cantril.

\subsection{Cantril's view of positive effects}

In his famous Patterns of Human Concern, Cantril reported on a first worldwide survey study. This study involved interviews with representative samples of the population in 14 countries selected to represent differences in economic development. Interviews took place in 1960. In all countries happiness was assessed by means of an ingenious interview technique. ${ }^{1}$ He found reported life satisfaction to be higher in the economically most developed countries: The rank correlation between average life satisfaction and his index of economic development was +.67 (Cantril, 1965, pp. 193-195).

Cantril suggested two reasons for this statistical relationship. Firstly, citizens in the poor countries would be "objectively deprived", their economic system failing to provide minimal necessities. Secondly, inhabitants of the poor countries would also be the victim of "subjective deprivation": the awareness that life is better in the rich world, lowering the appreciation of their own.

\subsection{Easterlin's claim that wealth does not buy happiness}

In the late sixties the ideological tide changed. The newly emerged Consumption Society came under fire. The satisfactions of mass consumption were discounted as "false happiness". "Real" satisfactions were projected in inner self-actualization and social utopias. In this climate of opinion an article by Ronald Easterlin with the title: "Does money buy happiness?" (Easterlin, 1973; expanded in Easterlin, 1974) received much attention.

Easterlin had re-examined Cantril's data. Instead of Cantril's multiple index of economic development he considered GNP per head only. He found the differences in life satisfaction between rich and poor countries rather small and not quite consistent (1974, p. 106). In a different set of nine countries he failed to find any strong relationship either ( $\mathrm{p}$. 107). Easterlin also made comparisons over time. He examined whether the post-war economic upsurge in the USA had resulted in a greater satisfaction with life. He found no effect at all. In spite of a doubling of the national income between 1945 and 1970, Americans had remained equally happy (p. 109). Yet people appeared not insensitive to the riches, surveys in various countries showing more life satisfaction in the high-income brackets than in the low ones (pp. 99-104).

On the basis of these observations Easterlin concluded that happiness is essentially relative. The enjoyment of life does not depend on the actual quality of living conditions, but rather on the degree to which one considers oneself better off than others, one's compatriots in particular. Easterlin illustrated this point with the analogy of "height". A European of one and a half meters will currently consider himself to be "short," even though this size was quite respectable in the Middle Ages and is considered tall among the Pygmies (pp. 116-118). 
This view has been corroborated in various studies in related fields. Experiments by van Praag and Kapteyn (1973) showed, for instance, that salary increases tend to inflate aspirations and therefore do not have a lasting effect on income satisfaction, while Brickman, Coates, and Janoff-Bulman (1978) demonstrated that lottery winners are no happier than average, and permanently injured accident victims not noticeably unhappier.

\subsection{Zolatas' view of declining wellfare effects}

The "Limits to Growth" movement that emerged in the early seventies called attention to various "costs" of affluence. The costs of mass consumption were vividly sketched by Hirsch (1976), in particular the negative effects of increased car-ownership. In his opinion individuals gain little because they must pay high mad taxes but still get stuck during rush hours, yet they cannot revert to a deteriorated public transport system. At the collective level mass ownership of cars has devastating consequences in terms of traffic accidents, pollution, and loss of scenery. Scitovsky (1976) emphasized the costs of mass production. Not only is the required assembly-line work alienating for the workers, but its products do not provide consumers with much pleasure either. Consumption goods produced in our economy provide sullen "comfort" rather than "stimulation". The development of mass persuasion techniques will nevertheless make people buy and will, in fact, create unappeasable "false" wants. More recently, the costs of collective welfare came to be recognized. State-provided health care and social security tend to dissolve informal social networks, the family in particular. This leads us into loneliness and makes us vulnerable to the cuts in social security that are inevitable when the system renders itself unpayable.

In his book Economic Growth and Declining Social Welfare, Xenophon Zolatas (1981) reviewed these arguments and considered their implications for societies at different stages of economic development. He believes that the richer the country, the more likely it is that the costs of economic growth outweigh its benefits. Thus he comes to suggest a curvilinear pattern, depicting a declining yield of economic growth which may even turn to the negative.

Zolatas does not focus on life satisfaction, but speaks more broadly about "quality of life" and "social welfare". Nor does he provide empirical data on the relationship between individual happiness and national economic prosperity. Yet his view is obviously of interest for the - more focussed - discussion at hand here.

\section{PREDICTED EFFECTS OF NATIONAL ECONOMIC WEALTH AND GROWTH ON INDIVIDUAL HAPPINESS}

The three views just outlined predict different configurations of happiness and wealth which are shown in Scheme 1.

Cantril's view implies that a comparison of average happiness between countries that differ in affluence must produce a positive linear pattern (Scheme 1a). Comparisons over time should reveal parallel variation in economic growth/decline and average happiness in the separate countries (Scheme 1b)

Easterlin's view also predicts that the plotting of national wealth against happiness produces a linear relationship, but this time a zero one, as symbolized by the horizontal line in Scheme 1c. Comparison over time would show a similar horizontal line, happiness being insensitive to economic growth and decline (Scheme 1d).

Zolatas view predicts that happiness follows a curvilinear pattern in both cases. The higher the levels of affluence, the less its happiness returns, and at some point the effects may 
even become negative (Schemes 1c and 1f).

Below I will examine which of these predictions comes closest to the facts. To that end I will first reconsider earlier empirical claims, in particular those of Easterlin. Next I will introduce some new information based on a secondary analysis of two large-scale crossnational surveys. I will consider the patterns that emerge from comparisons among nations of different economic development as well as the variation of happiness over time along with economic growth and decline.

\section{HAPPINESS IN RICH AND POOR COUNTRIES}

As noted above, current findings have been interpreted differently. I will try to resolve the issue by considering the disputed data in detail and by presenting a replication.

\subsection{Eaterlin's analysis is misleading}

The dispute is primarily about the interpretation of Cantril's data. Cantril claimed that his results show there is more happiness in the rich countries, while Easterlin held that there is hardly any difference.

Easterlin supported his claim by presenting Cantrils data graphically; see Scheme 2a. He argues that most countries are at the medium level (indicated by horizontal lines) in spite of great differences in GNP. Yet this presentation is misleading, Easterlin playing the classic trick of manipulating scales.

In Easterlin's presentation the GNP variable is depicted on a scale 2.5 times larger than the happiness scale. Thus the pattern is flattened. When both variables are awarded equal scales, a different picture emerges.

Rather than a horizontal line the plot produces an ascending curve; see Scheme $2 \mathrm{~b}$.

Beside Cantril's 14 countries, Easterlin compared another set of nations as well. These are the nine nations enumerated in Scheme 6, in which Gallup polls in 1965 had included identical questions on how happy one felt. Easterlin stated that these data leave one "uncertain" whether there is a positive association between GNP and happiness (p. 118). That contention is dubious as well. At first glance one can see a clear - though not perfect relationship. To make sure, I computed the product moment correlation on the basis of the data Easterlin presented in Table 7 of his article: $r=+.59$. Taking into account that correlations based on aggregate data tend to be high, this is still a relationship one can hardly characterize as "uncertain".

\subsection{New world survey shows a positive curvilinear relationship as well}

It is likely that even the two sets of data shown above do not depict the relationship to its full extent. In both sets of nations the very poor countries are underrepresented. Therefore, I examined the same relationship in the data of a large scale "World Survey" from 1975 (Gallup, 1976/77). This study sampled parts of the world rather than nations. It covered the poor regions of the Southern Sahara region of Africa and South East Asia. Unfortunately, the communist world, North Africa, and the Middle East could not be included. For the purpose of this paper it suffices that the poorest parts of the world are represented.

The Gallup World Survey assessed life satisfaction in essentially the same way as Cantril's earlier study (instead of a ladder, a mountain-like rating scale was used), and 
presented average scores for seven parts of the world and some well-represented nations. Like Easterlin, I cross-tabulated the averages ${ }^{2}$ with GNP. ${ }^{3}$ A clear relationship emerged; see Scheme 3. The correlation between happiness and GNP in this world sample is +.85.

As can be seen in Scheme 3, the relationship is again curvilinear. The difference in happiness between the "very poor" and "rather poor" regions is far greater than the difference between the "rather poor" and the "rich regions. When we omit Africa and Asia, hardly any relationship is left. This is, in fact, what happened to Easterlin. It also happened to Inglehart, who found no difference between rich and very rich countries in his analysis of happiness in the EC countries in 1975 (Inglehart, 1977, p. 150).

HAPPINESS DURING ECONOMIC RISE AND DECLINE

Easterlin's main piece of evidence was that Americans did not become happier between 1946 and 1975, in spite of a doubling of the GNP during that period. Does this example prove his general claim that happiness depends on social comparison and is therefore insensitive to collective movements towards better or worse? I will show that it does not.

\subsection{In post-war Europe wealth and happiness rose together}

Americans were already quite happy in 1946: 40\% claiming to be "very happy" and 50\% "fairly happy". At this level room for improvement is obviously small, not least because there is always a margin of inevitable unhappiness due to illness and mental disturbances. Increases in wealth may affect happiness more in countries where dissatisfaction prevails.

Likewise, we should not forget that the USA was already fairly affluent at the end of World War II. If wealth is subject to the law of diminishing returns, it is thus quite comprehensible that further increase did not add much to happiness. Yet matters are likely to be different in countries that start with a lower standard of living.

These points are neatly illustrated by the case of Western Europe. At the end of World War II happiness was low in England, France, the Netherlands, and West Germany. The level of living was low as well, housing shortage and food rationing being the rule. Between 1948 and 1975 these countries witnessed both a startling economic recovery and a general rise in happiness. The percentage of unhappy persons in the population was halved during that period (Veenhoven, 1984, p. 171).

In the 1970's Western Europe had become about as happy and affluent as the USA earlier Hence it is not unlikely that the continued --though slower-- economic growth in the later decades did not add that much to the enjoyment of life. Inspection of the Eurobarometer surveys data shows that this is indeed the case; see Scheme 7. Responses to the questions about "life satisfaction" remained largely at the same level, while favourable responses to the "happiness" item increased by some $15 \%$.

5.2 The last few decades economic fluctuations affected happiness in europe with some delay Easterlin's conclusion is too easy for another reason: The fact that American happiness did not rise during the post-war decades does not mean that it remained static all the time. In fact, happiness fluctuated somewhat over the years. It is possible that economic ups and downs affected at least these surface ripples. If so, that would not fit Easterlin's social comparison theory. If everybody is affected similarly, comparisons should not turn out differently.

The following reports on an empirical check of this possibility undertaken by myself and Piet Ouweneel (more details in Ouweneel, 1987). It is also based upon the Eurobarometer 
surveys, covering the period between 1975 and 1986, during which considerable economic fluctuations took place.

\section{Data}

The Eurobarometer survey involves bi-annual polls in each of the EC countries. The standard questionnaire involves two items on happiness. ${ }^{5}$ On the basis of frequency tables in the Eurobarometer Report No. 24, yearly happiness averages were computed for each of the EC countries and the EC as a whole. Next, the year-to-year changes in happiness were transformed into a percentage of the earlier year's average. This procedure was followed for both happiness items. Changes varied from $+12 \%$ to $-8 \%$. Fluctuations in average happiness were greatest in the years 1976 to 1979 .

Fluctuations in the standard of living in the EC countries were measured by growth rates in real GNP per head at market prices (OECD, 1986). To avoid scale problems, the growth rates were also expressed as a percentage of the earlier years' rate. These fluctuations varied from $+5 \%$ to $-1 \%$ and were also relatively great in the late seventies.

Analysis

We first considered whether happiness varies simultaneously with the economic tide, i.e., whether changes in the same direction tend to occur in the same year. For that purpose we plotted the change scores of both happiness and GNP and inspected the graphs. We also computed product-moment correlations. We did so for all ten EC countries and for the EC as a whole. These analyses were performed for the two happiness items separately.

In addition to this analysis of simultaneous covariation, we considered the possibility that economic changes have a delayed effect on happiness. It is not unlikely that macroeconomic growth and decline affect most citizens only at a later point in time. In a study in Kansas City, USA, Calatano, Dooley, and Jackson (1981) found the number of admissions to mental health facilities increased during the two to four months following the onset of a recession. Since our data provide yearly averages only, we assessed correlations at time lags of one and two years.

Lastly, we also checked whether changes in happiness precede economic change. Similar to more specific economic attitudes such as "economic optimism" and "consumer trust", life satisfaction could indeed affect economic behaviour. There is, for instance, evidence that a positive appreciation of life fosters an optimistic view of the world and stimulates activity (Veenhoven, 1984, pp. 285-287, 293). Therefore, we looked at the correspondence between economic fluctuations and variation in happiness one and two years earlier.

\section{Results}

At first sight the data confirm Easterlin's contention that fluctuations in national wealth are irrelevant for the individual's appreciation of life.

The analysis of simultaneous correlations reveals no consistent correspondence. Yet, when the time perspective is changed, a clear pattern emerges. Happiness appears to follow fluctuations in the economy; see Scheme 4. 
Scheme 4 shows that the $6 \%$ economic upsurge in 1975-76 was followed by a $12 \%$ rise in happiness in the years 1976-77. Likewise the 3\% economic decline that occurred between 1976 and 1977 manifested itself only between 1977 and 1978 in an 8\% drop in happiness. The more gradual pattern of declining economic growth between 1977 and 1981 is followed by an equally gradual diminishing of yearly happiness gains in 1982 and 1983 . The zero growth in 1981 corresponds to a slight drop in happiness in 1983. The quite limited economic recovery after 1981 is followed by an equally minimal rise in happiness from 1983 onward. The correspondence is highest at a one-year interval. For the EC as a whole $r=+.56$.

Similar correlations appear in the individual countries, with the exception of Germany and Luxembourg (zero correlation) and Eire (negative correlation); see Scheme 8.

The two individual happiness items produce similar patterns, though the question of how "happy" one feels appears to be more sensitive to economic fluctuations than the question about "satisfaction with one's way of life". The difference may be due to two things: Firstly, the "happiness" item focuses more on current feelings ("these days," see Note 5) and is therefore more likely to reflect short-term economic fluctuations than the "satisfaction" item that, in fact, covers one's whole life. Secondly, the somewhat distant judgement elicited by the latter question may be leveled off somewhat by cognitive adjustments, while the happiness item could more pronouncedly reflect the "raw" experiences of hope and despair.

The hypothesis that economic rise or decline is caused by an earlier change in happiness was not supported by these data.

DIMINISHING HAPPINESS RETURNS OF ECONOMIC WEALTH AND GROWTH

\subsection{The empirical pattern}

Scheme 5a represents the pattern of diminishing utility of macroeconomic welfare that appeared both in the cross-national comparison and in the comparison over time in post-war Western Europe.

Scheme $5 \mathrm{~b}$ represents the effects of short-term economic fluctuations. The solid part of that line represents the pattern of oscillations around the same level of happiness observed in Western Europe during the last decade. The intermittent extension of the thin line to the left reflects a hypothesis held by the author. I expect economic fluctuations to affect happiness in less affluent countries even more pronouncedly. There are at least two reasons for this expectation. Firstly, consequences in terms of need gratification are greater at the poorest end of the curve. Secondly, costs of growth are likely to be greater at the affluent end and are therefore likely to neutralize the effects of growth and decline to a greater extent. Scheme 5 provides a schematic representation of the findings.

\subsection{Predictions checked}

Which of the predictions presented in Scheme 1 meets this observed pattern best? Clearly not Easterlin's. His claim that individual happiness is insensitive to the economic condition of the nation holds only in the stratum of affluent societies, and even there does not predict the observed short-term variation of happiness with the economic tide. Cantril's is more adequate. It fits both the observed greater happiness in rich countries and the fluctuations in happiness following economic rise and decline. Zolatas' does even better. The curvilinear pattern he predicted did in fact emerge, though there is no evidence for the drop to the negative he held to be possible at the greatest level of affluence. 
Of the three views presented in the beginning of this paper Easterlin's is the best known. It figures in many textbooks. Easterlin's theory is, in fact, accepted as one of those remarkable research results that seems counter-intuitive at first sight, but marks the superiority of scientific understanding. Yet it is simply wrong. Empirically it depicts an exception rather than a rule and theoretically it is very one-sided (to be argued below). I wonder whether the "world" will ever discard this theory, or whether its celebrity will keep the misunderstanding alive.

\subsection{Explanations checked}

Let us now consider in more detail the explanations proposed for the predicted relationships. How well do these meet the pattern that actually emerged?

\subsubsection{Social comparison}

Though the facts are not as Easterlin presumed, his theory may still make some sense. Hence it is worth dwelling on the possibility that a social comparison theory can explain the observed pattern.

However, the observed differences between rich and poor countries can hardly be explained by social comparison theory. Explaining the fact that any difference at all exists would require that people compare their situation with foreigners rather than with compatriots. This is not probable. Reference groups tend to be close, and most people have only dim ideas of the standard of living in other parts of the world. Moreover, the curvilinear pattern can be accounted for only if we assume that Indians and Africans compare themselves with the rich world more frequently than do Latin Americans and the Japanese. The reverse seems to be the case.

Nor can social comparison theory account for the fact that oscillations in happiness were found to follow economic fluctuations. As noted earlier, economic ups and downs lend to affect everybody to approximately the same degree. Hence, social comparison theory can apply only in special cases, for example, where people notice changes in their own finances more clearly than fluctuations in the general level of living, or when economic fluctuations cause a redistribution of income. I will not discuss all the possibilities here. Let it suffice to note that extra assumptions are required to make social comparison theory fit these data.

If comparison is involved at all, comparisons of ones own situations over time are more likely to be involved. Happiness could decrease somewhat when people notice that they can no longer afford the things they were used to, whereas it might be boosted slightly when one perceives progress and expectations are surpassed. Cognitive mechanisms are likely to neutralize these changes to a great extent. Habituation and inflation of expectations may soon reduce the joys of economic growth, while people adjust in similar ways to decline, as long as no basic needs are frustrated.

At a more basic level, it is not very plausible to assume that human happiness depends entirely on comparison. Why would nature have left us with a tendency to orient ourselves towards such arbitrary standards of the good life?

\subsubsection{Need theory}

The theory Cantril hints at rather assumes that happiness depends on the gratification of universal "basic needs". Such needs are presumed to have evolved in the human species because their pursuit has survival value. Various attempts have been made to grasp what 
these needs involve. The best known of these is Maslow's (1968) theory which proposes a hierarchically ordered set of needs for physiological "subsistence," "safety," "belonging," "esteem," and "actualization". This theory fits the observed pattern of differences in happiness between poor and rich nations better. Basic needs for food, shelter, and safety are clearly less well met in the poor countries, as is demonstrated in the relatively short average life-expectancy of their citizens. Need theory also explains the curvilinear pattern more easily. Maslow's theory holds that so-called "deficiency needs" tend to lose salience once reasonably satisfied. Diminishing satisfaction from extra gratification is the result. This view would imply that economic wealth is less relevant for the higher "being needs" which Maslow presumes to be infinite.

Need gratification theory can less easily explain the short-term effects of economic rise and decline on happiness in the rich EC countries. Not only did the recession not involve any threat of subsistence, but the effects were also short-lived. Still, need theory can account for this phenomenon if one assumes that the deprivations caused by economic recession are largely symbolical. Feelings of safety are likely to have been shattered in many persons and mass unemployment has certainly frustrated "esteem" needs, and in many cases, also the need for "belongingness". The recuperation that appears can then be explained by a reorientation, both at the individual level (e.g.. seeking other meaningful tasks) and at the societal level (e.g., boosted optimism, changed attitudes to unemployment). This reorientation is a more active way of coping than the comparison theory explanation of this phenomenon in terms of resignation. Though economic growth, too, may involve similar disruptive effects, these are likely to be less frequent: growth leaving the individual more room for self-determination than decline. Hence, economic prosperity can allow people better opportunities to follow a way of life that meets their needs and can thereby result in more enjoyment of life. As "freedom of choice" is the critical variable here, the effects depend more on turns in the economic tide than on the level of affluence. This can also explain the short-livedness of the effect. Obviously, the surplus of freedom allowed by economic prosperity depends on the socio-political context. National variations are therefore likely.

\subsubsection{Cost of affluence}

Though Zolatas' prediction was closest to the observed pattern, not all of his reasoning is equally convincing. Part of his argument follows the above line of basic need theory, but he also points out the drawbacks of affluent society (false wants, dull products, commuting, pollution, undermining of family). These latter effects could bend the curve towards the negative, while the satiation of needs can at best reduce the effect of wealth to zero. It may be true that the negative side-effects of affluence tend to counterbalance the positive effects. Yet it is difficult to establish whether the costs of affluence are really disproportionally high in the rich countries. One could make a good case for the contrary as well, for example by arguing that production conditions in the poor countries are even more alienating than they are in the rich world, that consumer goods produced by subsistence economies are even more dull, and that material dependence on intimates burdens interpersonal relations. Anyway, since there is no sign of the curve bending towards the negative, there is no independent evidence for Zolata's explanation.

The pattern of short-lived oscillations in happiness following the economic tide with some delay cannot be explained in terms of costs of affluence. In fact, the theory would predict a lowering rather than a rise in happiness one or two years after an upsurge of the economy because of a "suffocation" through newly purchased goods and services, while economic decline should raise happiness after some time. Moreover, this explanation does not account for the short-livedness of the effects on happiness. It would, in fact, predict enduring change. 


\section{CHALLENGES FOR FURTHER RESEARCH}

As the above discussion indicates, our understanding of the mechanisms underlying the observed pattern of diminishing happiness returns by increasing affluence is still rather limited and speculative. It would be worth giving the matter more thought. One way of finding clues might be to look for differences in the bending of the curve. In other words, trying to identify conditions in which growth of affluence sooner or later catches up with the rise in happiness. It could be, for example, that the happiness returns of affluence are lower when economic development is paralleled by individualization, If so, patterns should differ between Western Europe and South-East Asia.

Another issue worth investigating is whether the delayed sequel of economic rise and decline we observed in "subjective" indicators of wellbeing also appears in "objective" ones. We could, for example, check whether the economic recession of 1980-1982 was followed by a rise in physical illness and mental afflictions. If not, the observed drop in happiness is apparently a surface phenomenon, to be attributed to comparison. In the other case "real" deprivations are more likely to be involved, as predicted by need theory.

\section{CONCLUSION}

The economic prosperity of the country does affect the degree to which its citizens enjoy life. In the poor countries people are clearly less happy than in the rich countries. However, the returns of wealth are subject to the law of diminishing utility. In the Western affluent societies the last few decades' economic growth hardly raised the average level of happiness. Still, in the rich countries, economic ups and downs result in fluctuations in happiness around an otherwise stable average level of high satisfaction.

These results contradict Easterlin's $(1973,1974)$ theory that happiness is socially relative and therefore essentially insensitive to collective economic conditions. The results can be fairly well explained in terms of Maslow's need theory. 


\section{NOTES}

1. Respondents were first asked to describe the "best possible" life they could imagine and next the "worst possible" life. Then a picture of a ten-step ladder was presented and they were asked: "Suppose the top of the ladder represents the best possible life for you, and the bottom the worst possible life for you, where on the ladder do you feel you personally stand at this time?" (Cantril, 1965, pp. 22-23).

2. Japan was taken separately because its economic development differs too much from the other countries in the Asia sample. The remaining sample is heavily dominated by India.

3. Data from World Bank Atlas (1971).

4. The Eurobarometer surveys have been held twice a year since 1975 in each of the EC countries.

The standard questionnaire involves two items on happiness (see Note 5). Spain, Portugal, and Greece were not included in the analysis, because these countries joined the EEC later and are therefore not represented in all the surveys. In the years 1980 and 1981 item 1 was not included.

5. The standard questionnaire of the Eurobarometer survey involves the following two happiness items: 1. Taking all things together, how would you say you are these days — would you say you are very happy, fairly happy, or not too happy these days?

2. On the whole, are you very satisfied, fairly satisfied, not very satisfied, or not at all satisfied with the life you lead? 


\section{REFERENCES}

Brickman, R., Coates, D., \& Janoff-Bulman, R. (1978).

Lottery winners and accident victims: Is happiness relative?

Journal of Personality and Social Psychology. 36, 917-927.

Cantril, H. (1965).

The pattern of human concern.

New Brunswick, NJ: Rutgers University Press.

Calatano, R., Dooley, D., \& Jackson, R. (1981).

Economic predictors of admissions to mental health facilities in a non-metropolitan community.

Journal of Health and Social Behavior, 22, 284-297.

Easterlin, R.A. (1973).

Does money buy happiness?

Public Interest, 30(30), 3-10.

Easterlin, R.A. (1974).

Does economic growth improve the human lot?

In: P.A. David \& W.E. Melvin (Eds.), Nations and households in economic growth, pp. 98125. Palo Alto, CA: Stanford University Press.

Eurobarometer (1985).

Report 24

Brussels: Commission of the European Community.

Gallup, G.H. (1976/77).

Human needs and satisfactions: A global survey.

Public Opinion Quarterly, 41, 459-467.

Hirsch, F. (1976).

The social limits of growth.

Cambridge, MA: Harvard University Press.

Inglehart, R. (1977).

The silent revolution: Changing values and political values among Western publics. Princeton, NJ: Princeton University Press.

Maslow, A.H. (1970).

Motivation and personality.

New York: Harper \& Row.

OECD (1986).

OECD Economic Outlook, No. 39.

Ouweneel, P. (1987).

Geluk volgt welvaart (Happiness follows prosperity).

Economisch Statistische Berichten, 1987, pp. 840-842. 
Scitovsky, T. (1976).

The joyless economy.

London: Oxford University Press.

van Praag, B.M.S., \& Kapteyn, A. (1973).

Wat is ons inkomen ons waard (How do we value our income)?

Economisch Statistische Berichten, 1973, pp. 360-361, 380-382.

Veenhoven, R. (1984a).

Conditions of happiness,

Dordrecht: Reidel.

World Bank Atlas.

Population, product, and growth rates in 1969(1971).

Washington, DC: International Bank for Reconstruction and Development.

Zolatas, X. (1981).

Economic growth and declining social welfare.

New York: New York University Press. 


\section{Scheme 1}
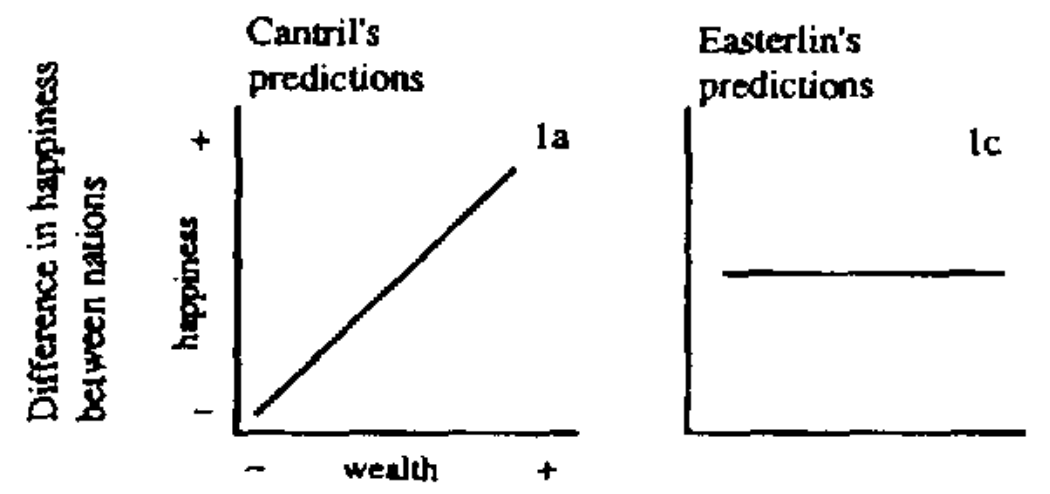

\section{Zolatas' \\ predictions}
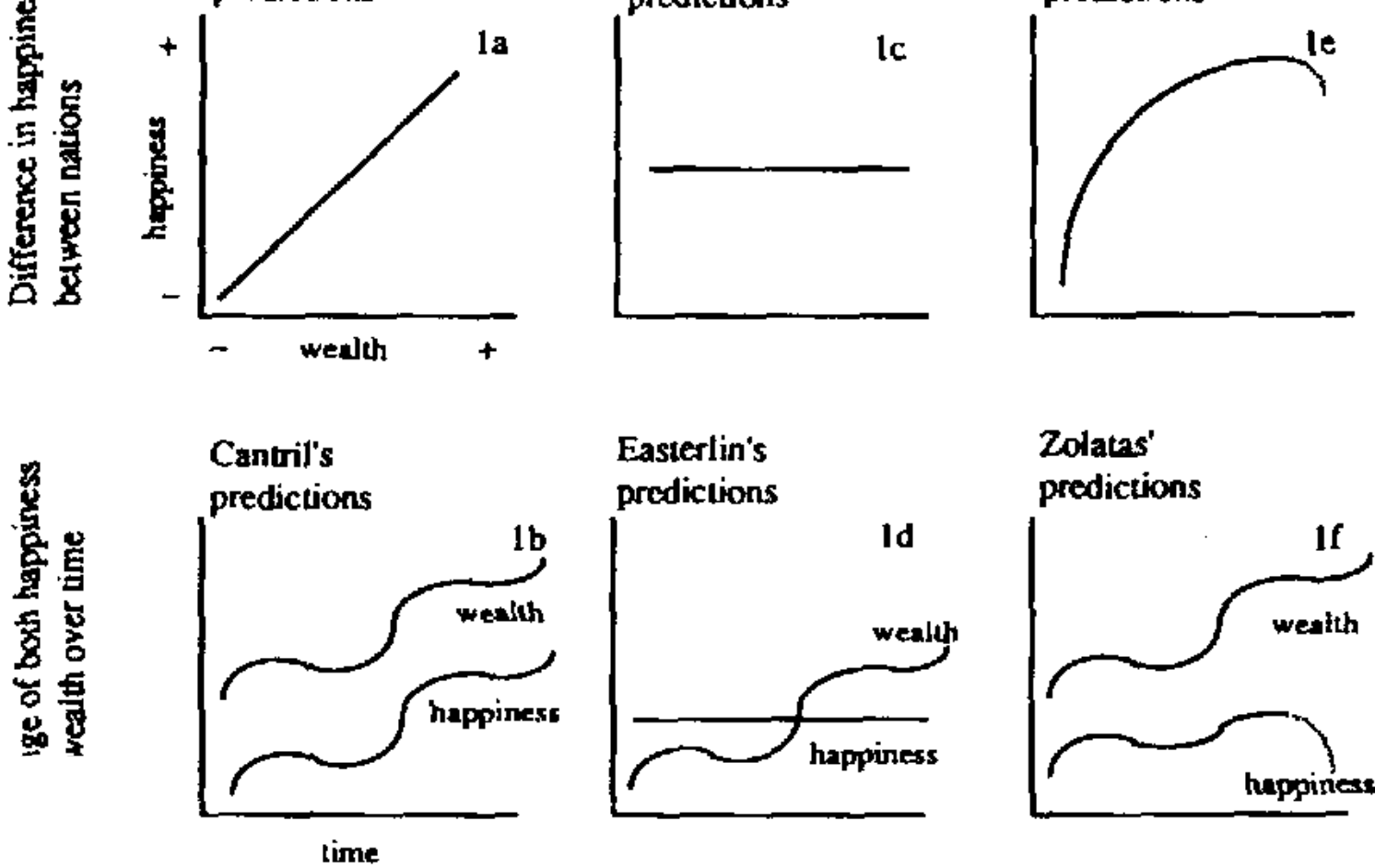

Zolatas' predictions

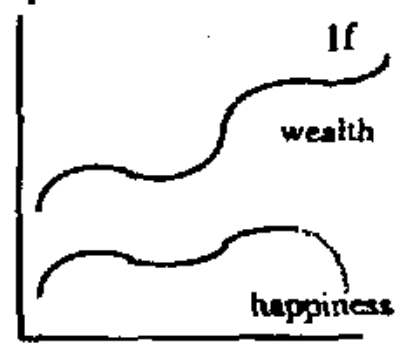

Predicted configuration of average happiness and economic wealth. 
Scheme 2

2a: Easterlin's presentation (Easterlin, 1974, p. 106)

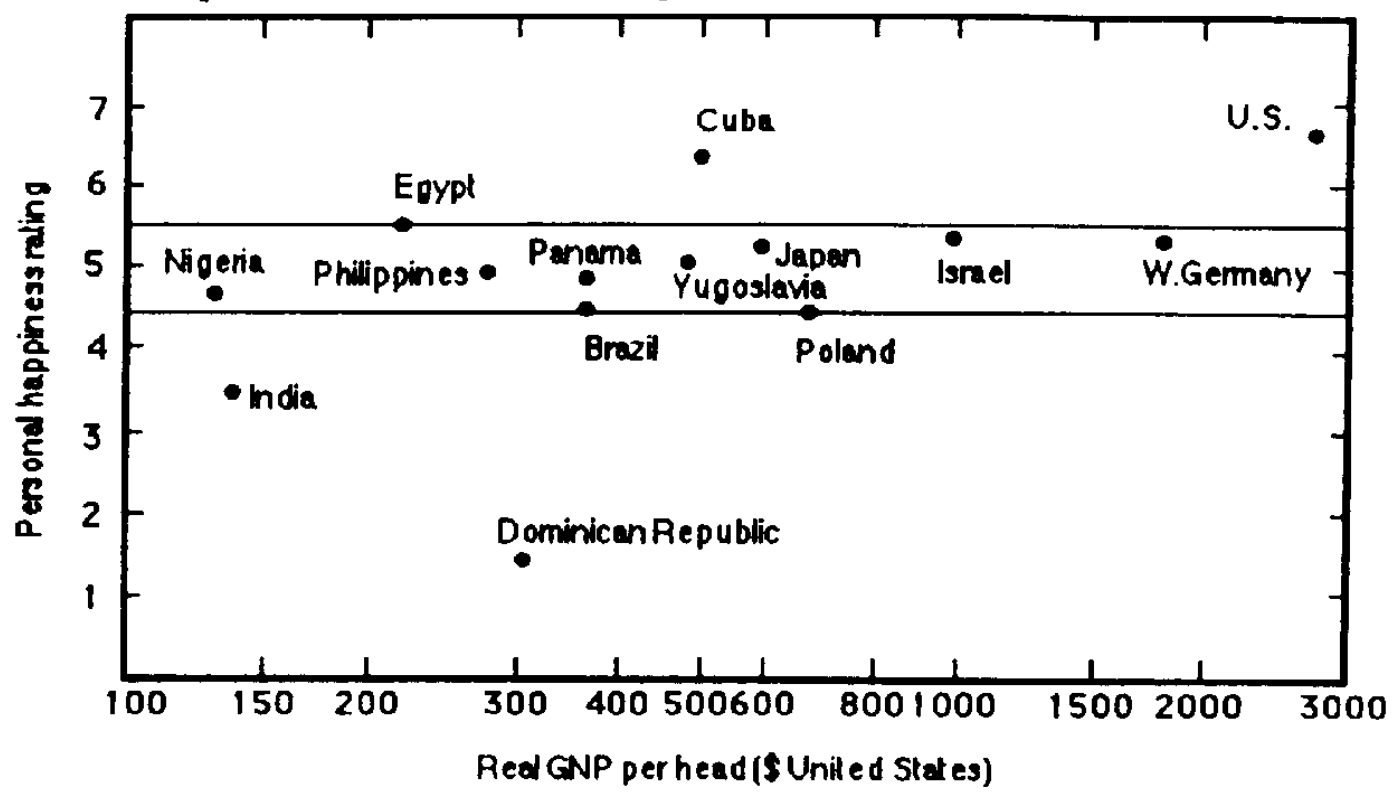

2b: My presentation (based on the same data)

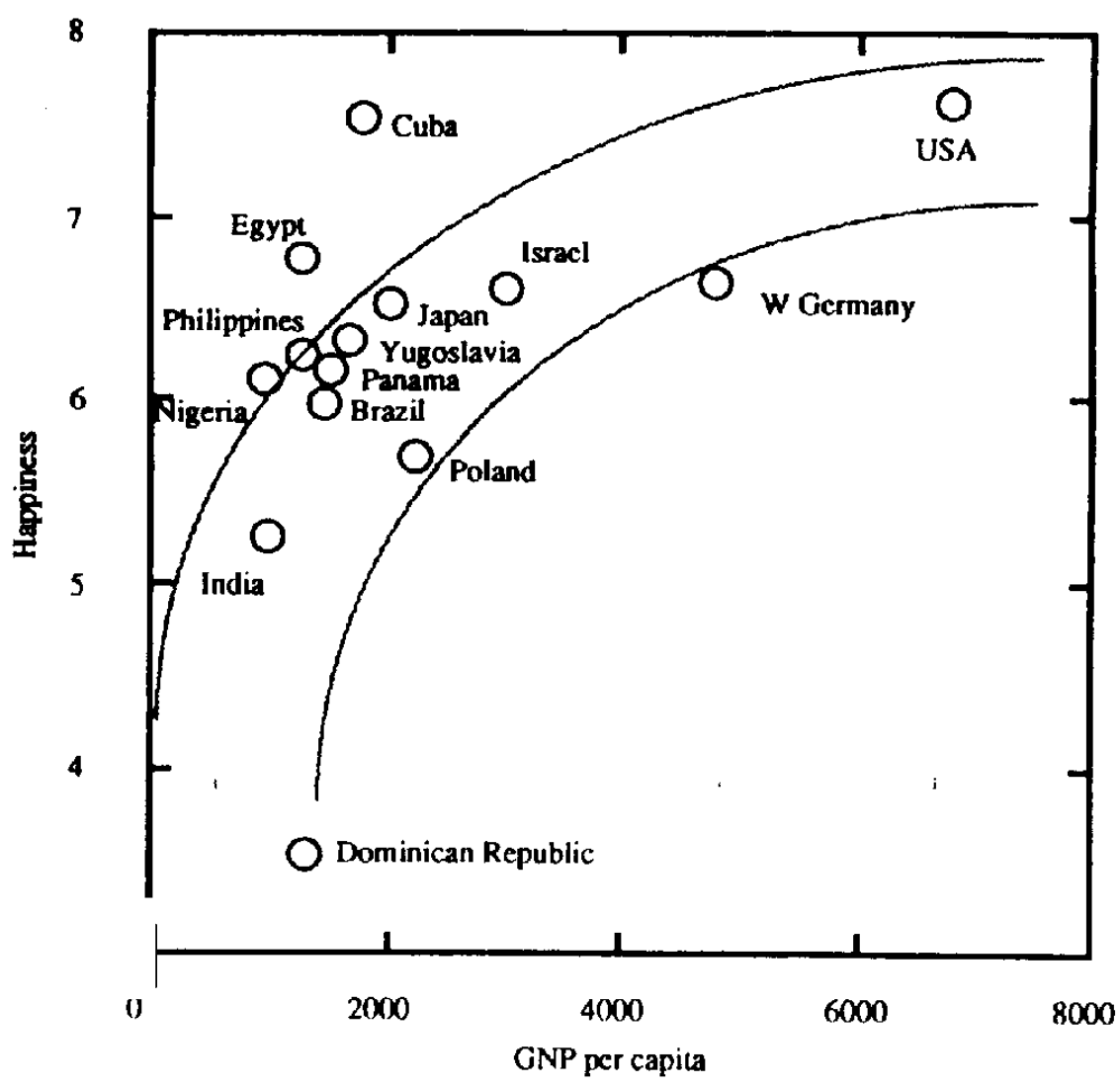

Presentations of Cantril's data on average happiness in countries of different wealth in $\mathbf{1 9 6 0}$. 
Scheme 3

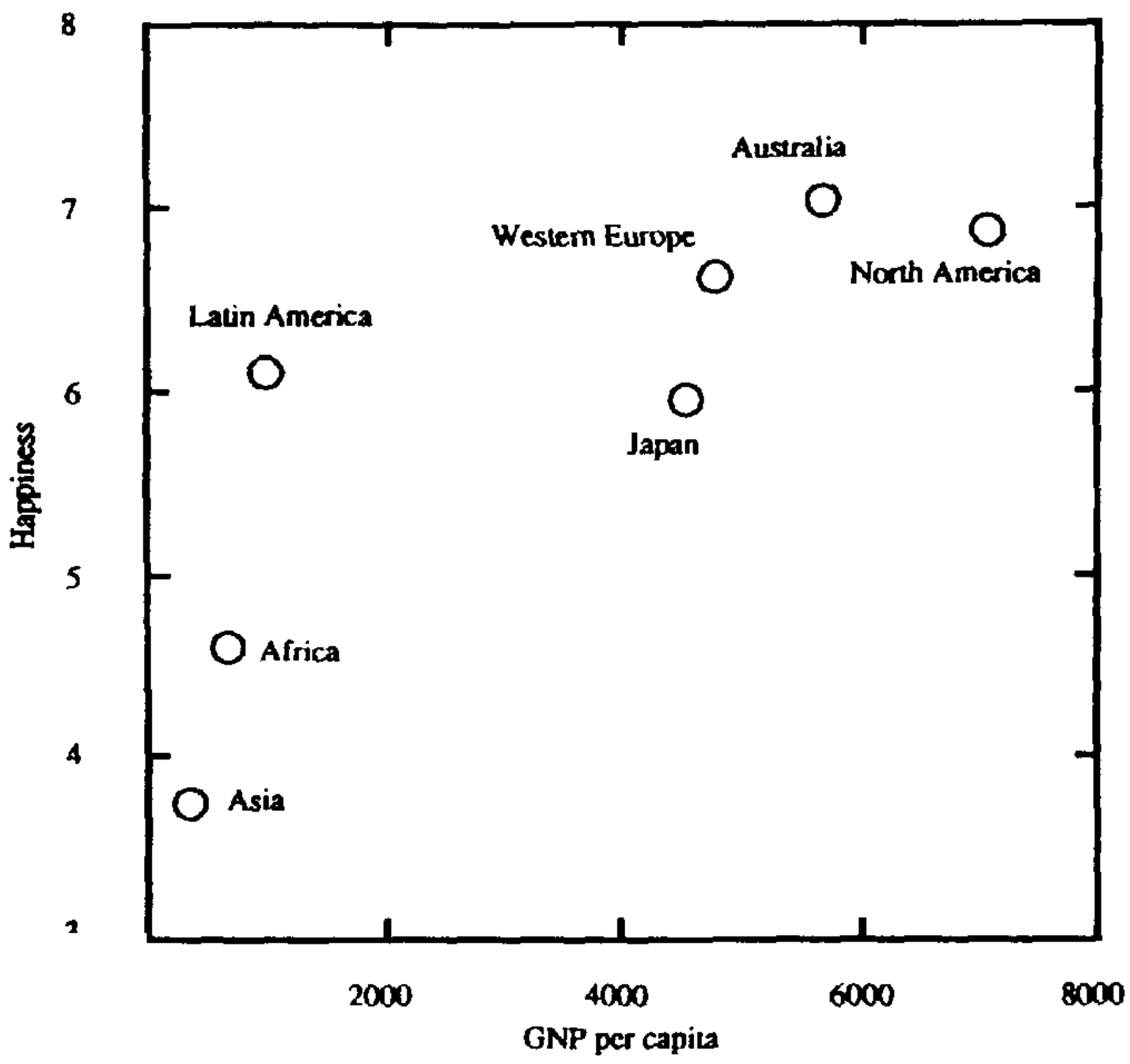

Happiness in seven parts of the world by GNP per head in 1975. Source: Veenhoven (1984, p. 149). 


\section{Scheme 4}

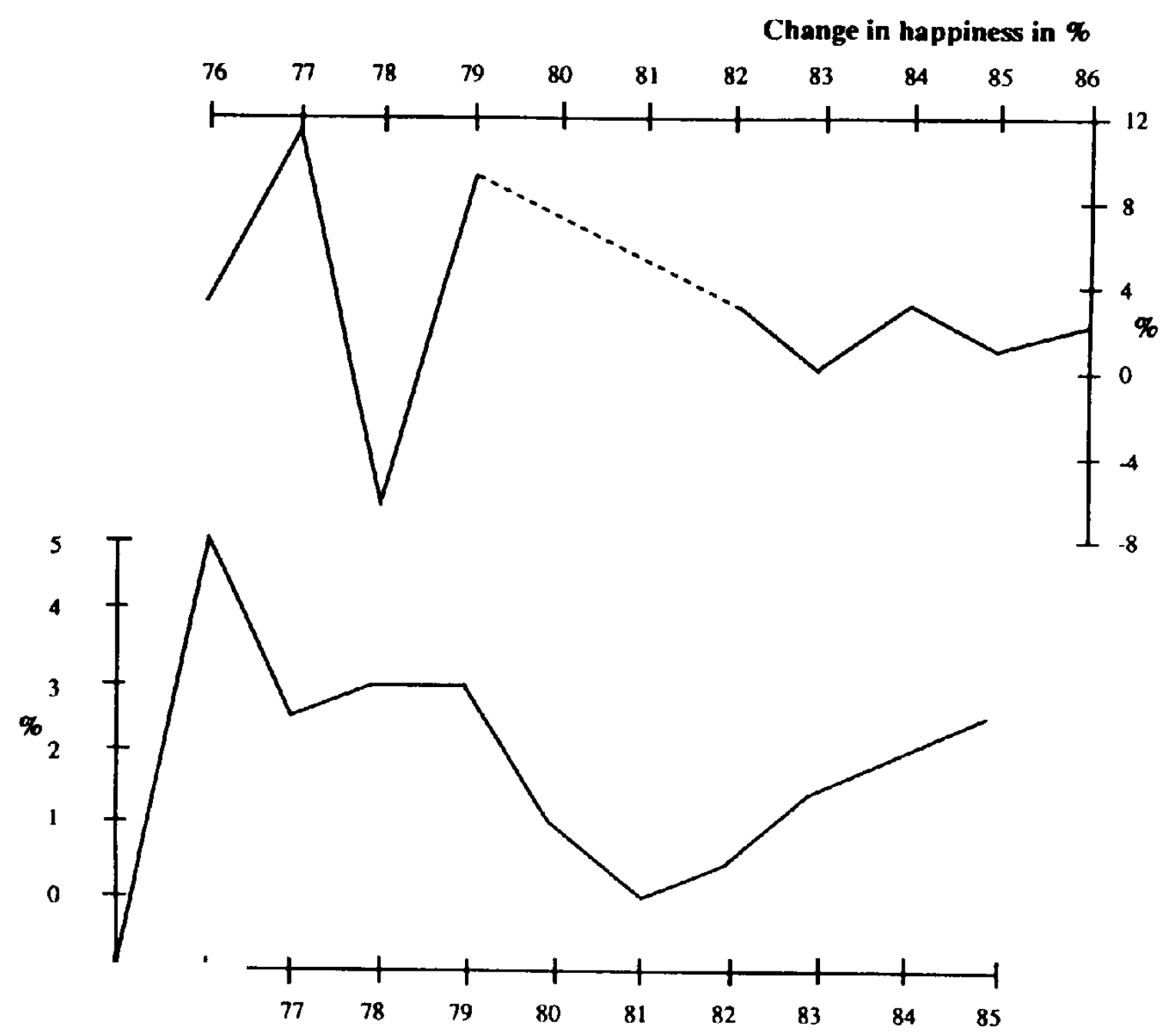

Change in GNP in \%

Year-to-year changes in happiness and changes in GNP per head between 1976 and 1986 in ten EC countries. 
Scheme 5

5a: The declining happiness revenue of national wealth

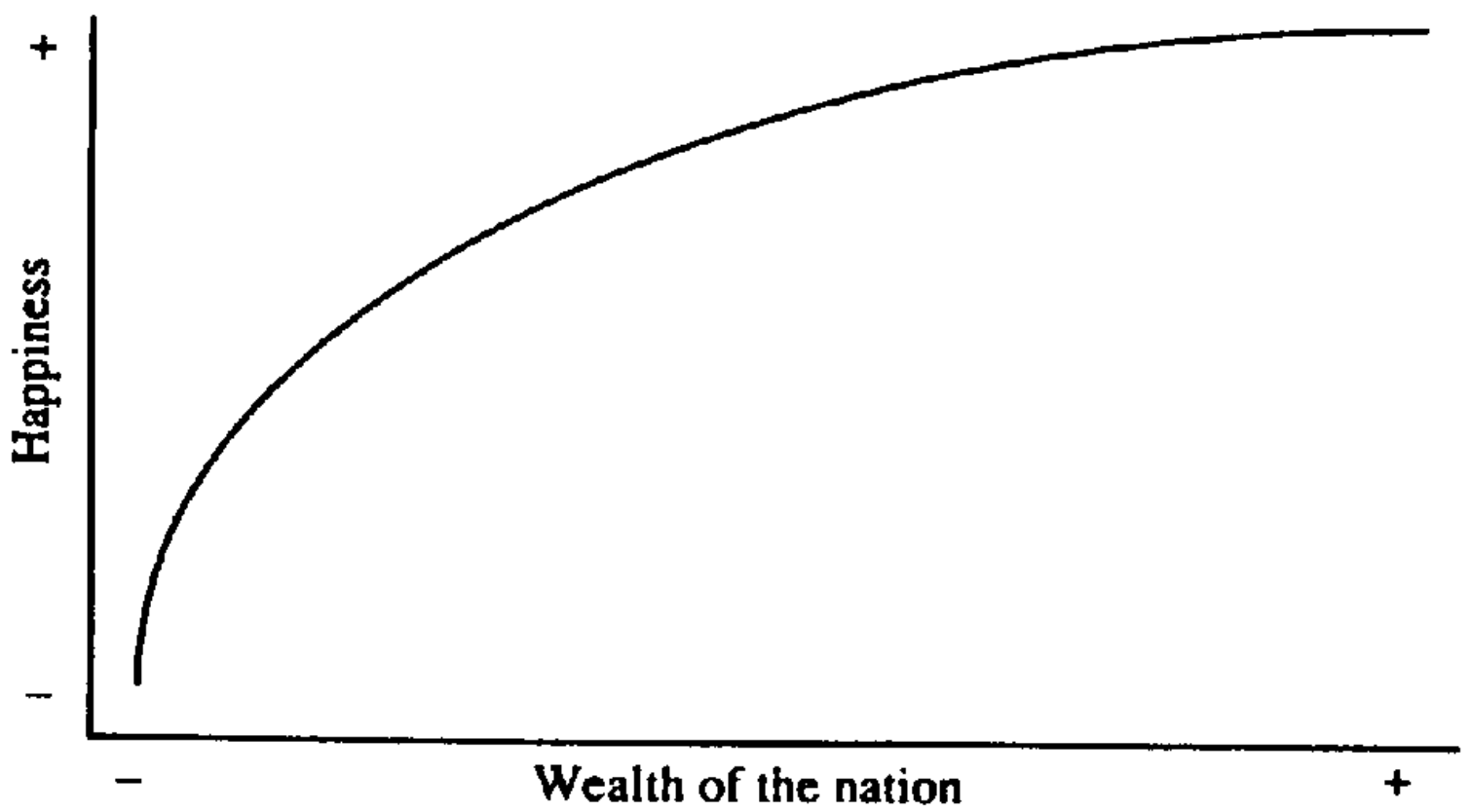

Sb: Declining susceptibility of happiness to economic fluctuations

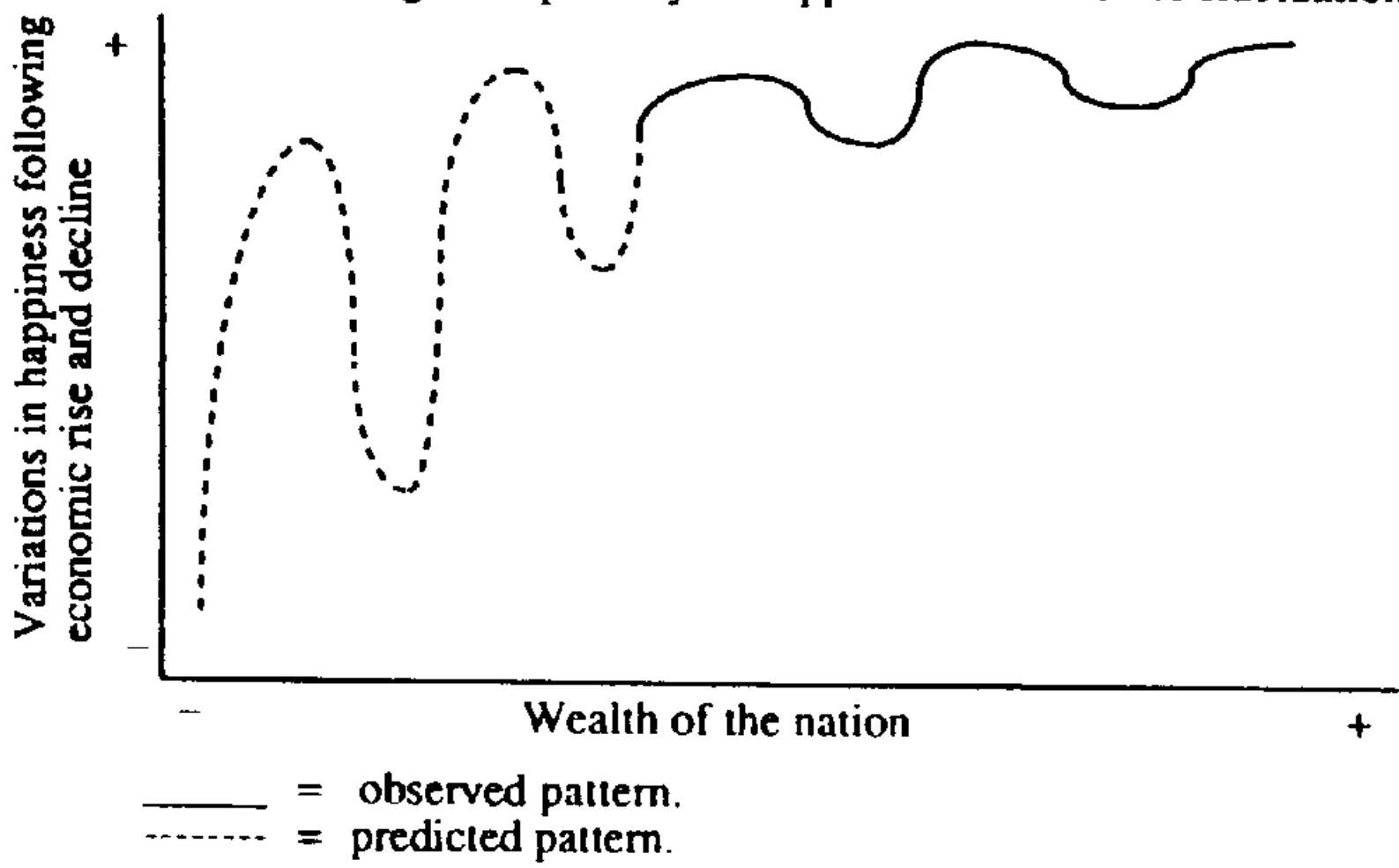

Schematic summary. 
Scheme 6:

\section{Second Set of Nations Compared by Easterlin}

\begin{tabular}{|c|c|c|c|c|c|c|}
\hline \multicolumn{7}{|c|}{$\begin{array}{c}\text { Percent Distribution of Population by Happiness, } \\
\text { Nine Countries, } 1965\end{array}$} \\
\hline Country & $\begin{array}{l}\text { Very } \\
\text { happy }\end{array}$ & $\begin{array}{l}\text { Fairly } \\
\text { happy }\end{array}$ & $\begin{array}{c}\text { Not very } \\
\text { happy }\end{array}$ & Other & $\mathrm{N}$ & $\begin{array}{c}\text { RealGNP } \\
\text { per head } 1961\end{array}$ \\
\hline Great Britain & 52 & 42 & 4 & 1 & 1179 & $\$ 1777$ \\
\hline United States & 49 & 42 & 4 & 2 & 3531 & $\$ 2790$ \\
\hline West Germany & 20 & 66 & 11 & 3 & 1255 & $\$ 1860$ \\
\hline Thailand & 13 & 74 & 12 & 1 & 500 & $\$ 202$ \\
\hline Japan & (a) & 81.0 & 13 & 5 & 920 & $\$ 613$ \\
\hline Philippines & 13.5 & 73 & 13.5 & 0 & 500 & $\$ 282$ \\
\hline Malaysia & 17 & 64 & 15 & 4 & 502 & $\$ 552$ \\
\hline France & 12 & 64 & I8 & 5 & 1228 & $\$ 1663$ \\
\hline Italy & 11 & 52 & 33 & 4 & 1166 & $\$ 1077$ \\
\hline
\end{tabular}

(a) Question read "not happy" rather than "not very happy".

Source: Easterlin (1974, p. 107. Table 7). 
Scheme 7:

Average Happiness in the EC Countries in the Years

1975-1986

\begin{tabular}{|lll|}
\hline Year & Happiness & Life satisfaction \\
& & \\
\hline 1975 & 2.33 & 2.90 \\
1976 & 2.30 & 2.90 \\
1977 & 2.55 & 2.97 \\
1978 & 2.39 & 2.97 \\
1979 & 2.59 & 2.94 \\
1980 & -- & 2.95 \\
1981 & -- & 2.92 \\
1982 & 2.45 & 2.95 \\
1983 & 2.42 & 2.90 \\
1984 & 2.48 & 2.95 \\
1985 & 2.48 & 2.87 \\
1986 & 2.52 & 2.97 \\
\hline
\end{tabular}

Derived from Eurobarometer Report No. 24. 
Scheme 8:

Correlations $^{1}$ of Yearly ${ }^{2}$ Fluctuations ${ }^{3}$ in GNP $^{4}$ With

Fluctuations in Happiness ${ }^{5}$ in the EC Countries Between 1976 and 1986

\begin{tabular}{|lcc|}
\hline Country & Same time $^{\mathbf{6}}$ & ${\text { One year } \mathbf{~ I a g}^{7}}^{7}$ \\
\hline Belgium & -.29 & +.88 \\
Denmark & -.31 & +.52 \\
Germany & +.28 & +.42 \\
Great Britain & -.73 & +.47 \\
France & -.13 & -.34 \\
Ireland & -.06 & +.70 \\
Italy & -.28 & -.12 \\
Luxembourg & -.18 & +.40 \\
Netherlands & \pm .12 & +.56 \\
\hline
\end{tabular}

1 Product-moment correlation.

2 Changes in both happiness and GNP from one year to another. Ten changes were observed.

3 Amount of yearly change expressed in percentage of the level of the foregoing year.

${ }^{4}$ BNP per head, in each year. Source: OECD (1986).

5 Average happiness in the country in each year. Assessed on the basis of Eurobarometer Report nr. 24.

${ }^{6}$ Covariation of change in happiness in a year with change in GNP in the same year.

(Ten year pairs compared for each country.)

${ }^{7}$ Covariation of change in happiness in a year to rise or decline of GNP a year earlier. (Ten year pairs compared for each country.) 